\title{
The Value of C-Reactive Protein in Enhancing Diagnosis of Acute Appendicitis
}

\author{
Mazhar H. Raja ${ }^{\text {a, c }}$, Elamin Elshaikha, Lisa Williams ${ }^{\mathrm{a}}$, \\ Mohamed H. Ahmed ${ }^{\mathrm{b}}$
}

\begin{abstract}
Background: Acute appendicitis is one of the most common surgical emergencies. Accurate diagnosis of acute appendicitis is based on careful history, physical examination, laboratory and imaging findings. The aim of this study was to analyze the role of C-reactive protein (CRP) in improving the accuracy of diagnosis of acute appendicitis and to compare it with the histopathology findings.
\end{abstract}

Methods: A retrospective study of 100 patients aged between 7 and 69 years who presented to the A\&E in 2013 - 2014, in whom the diagnosis of appendicitis was the attending physician's primary consideration, was conducted. Measures included age, gender, initial CRP counts, and discharge diagnosis. Based on histology, appendicitis was classified as simple (inflammation) or complicated suppurative, gangrenous, necrotizing perforation.

Results: Out of 100 patients, $32 \%$ were classified as an inflamed appendicitis. Of the patients, $34 \%$ were shown to have suppurative appendicitis, $17 \%$ gangrenous, $13 \%$ perforated, and $5 \%$ necrotizing. Very high CRP is likely to be associated with necrotizing appendicitis, while CRP of 40 or more can be associated with suppurative or inflammatory one. CRP more than 100 and less than 150 may suggest possible perforated or gangrenous appendicitis.

Conclusion: Our data provided provisional evidence that very high CRP may be related to necrotizing appendicitis, while CRP above $40 \mathrm{mg} / \mathrm{L}$ may suggest suppurative or inflammatory appendicitis.

Keywords: CRP; Appendicitis

Manuscript accepted for publication February 15, 2017

aDepartment of Surgery, Milton Keynes University Hospital NHS Foundation Trust, Eaglestone, Milton Keynes, Buckinghamshire, UK

bDepartment of Medicine and HIV metabolic clinic, Milton Keynes University Hospital NHS Foundation Trust, Eaglestone, Milton Keynes, Buckinghamshire, UK

${ }^{\mathrm{c} C o r r e s p o n d i n g ~ A u t h o r: ~ M a z h a r ~ H . ~ R a j a, ~ D e p a r t m e n t ~ o f ~ S u r g e r y, ~ M i l t o n ~}$ Keynes University Hospital NHS Foundation Trust, Eaglestone, Milton Keynes, Buckinghamshire, UK. Email: mazharhr@hotmail.com

doi: https://doi.org/10.14740/jcs316w

\section{Introduction}

Acute appendicitis remains a common surgical emergency in patients presenting with acute abdominal pain. Usual signs and symptoms described in textbooks are often in the elderly atypical, diminished or absent. Similarly in young children, signs and symptoms are non-specific, due to the wide range of causes and the inability to retell an accurate history. Therefore, appendicitis is a challenging diagnosis to make. Although clinical acumen remains the most important diagnostic tool in acute appendicitis, clinicians often rely on blood tests to support and improve the accuracy of diagnosis. The value of C-reactive protein (CRP) is very helpful in planning the management. It is vital in reducing the negative appendicectomy rates, currently in one recent audit study $20.6 \%$ [1].

CRP is an acute-phase reactant synthesized by the liver in response to infection or inflammation and rapidly increases within the first $12 \mathrm{~h}$. CRP has been reported to be useful in the diagnosis of appendicitis; however, it lacks specificity and cannot be used to distinguish between sites of infection.

CRP levels of greater than $1 \mathrm{mg} / \mathrm{dL}$ are commonly reported in patients with appendicitis, but very high levels of CRP in patients with appendicitis indicate gangrenous, perforation or suppurative evolution of the disease, especially if it is associated with leukocytosis and neutrophilia. However, CRP normalization occurs $12 \mathrm{~h}$ after onset of symptoms. Several prospective studies have shown that, in adults who have had symptoms for longer than $24 \mathrm{~h}$, a normal CRP level has a negative predictive value of $97-100 \%$ for appendicitis [24]. Shogilev et al noted that a normal CRP level after $12 \mathrm{~h}$ of symptoms was $100 \%$ predictive of benign, self-limited illness [3].

\section{Materials and Methods}

This was a retrospective study on 100 patients surgically treated for acute appendicitis. The measurement of CRP was randomly collected pre-operatively from 100 patients. Two patients were excluded as blood results were unavailable. Macroscopic assessment was made from the operation. Appendectomy and a histopathology examination were performed on all patients. Gross description was compared with histopathology results 


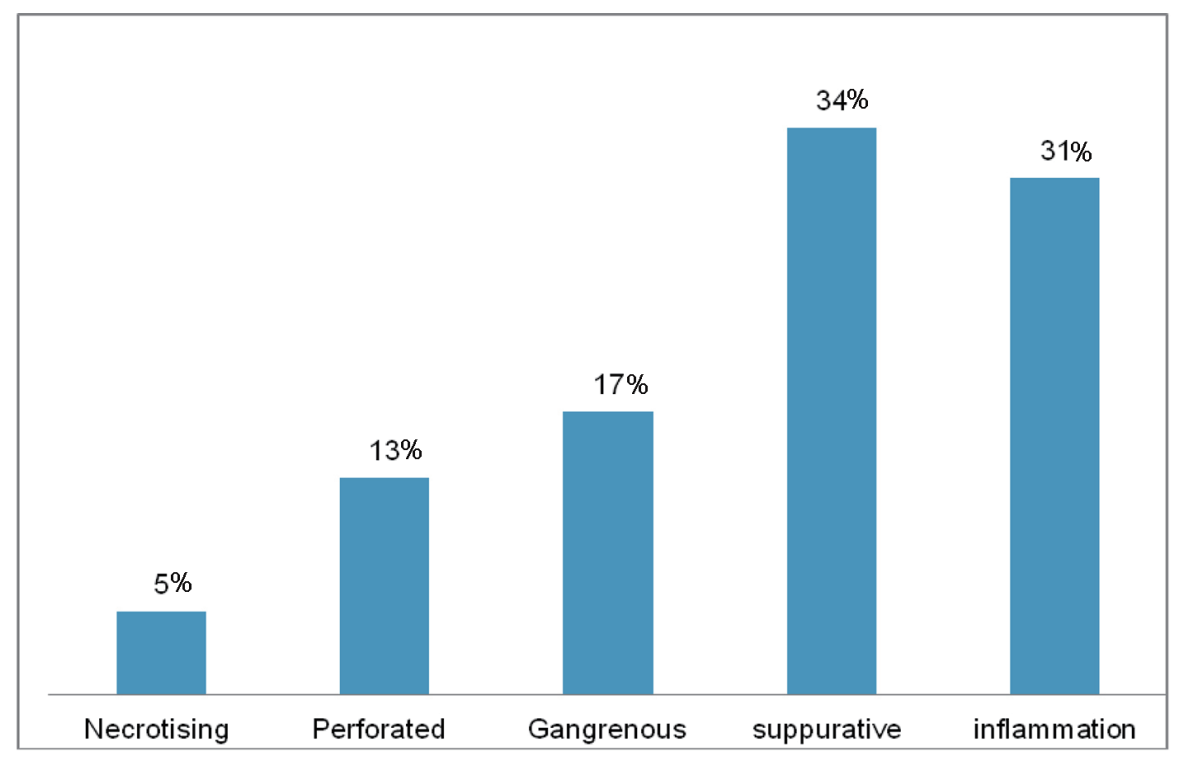

Figure 1. Percentage of the prevalence of different types of appendicitis. High prevalence was reported among suppurative and inflammation, while low prevalence was reported for necrotizing appendix.

and then correlated with CRP.

\section{Results}

Out of 100 patients, 32 were classified as an inflamed appendicitis, 34 patients were shown to have suppurative appendicitis, 17 gangrenous, 13 perforated, and five necrotizing. All the distribution of percentage is depicted and shown in Figure 1.

Overall in the inflammation and suppurative groups, the CRP was normal in 22 out of 64 patients. Complicated appendicitis included gangrenous, perforated and necrotizing. WBC was normal in five over 35. CRP was normal in one out of 35 .

Relationship of CRP with WBC to correlate with distribution of confirmed pathologies is shown in Figure 2.

\section{Discussion}

The raised value of the CRP was related to the severity of inflammation in more than 90\%. CRP monitoring enhances the diagnostic accuracy of acute appendicitis. Given the fact that the diagnosis of acute appendicitis remains mostly clinical, we found that elevated serum CRP levels support the surgeon's clinical diagnosis. This has been supported further in the literature. Multiple studies have examined the sensitivity of CRP level alone for the diagnosis of appendicitis in patients selected to undergo appendectomy. Gurleyik et al noted a CRP sensitivity of $96.6 \%$ in 87 of 90 patients with histologically proven disease [5]. Similarly, Shakhatreh found a CRP sensitivity of $95.5 \%$ in 85 of 89 patients with histologically proven appendicitis [6]. Asfar et al reported a CRP sensitivity of $93.6 \%$ in 78 patients undergoing appen- dectomy [7].

Group A means inflammatory and suppurative; total patients were 64 and out of these 22 CRP values were negative, which in this group shows the sensitivity of $66 \%$. Group B includes gangrenous, perforated, and necrotizing, and the sensitivity is $97 \%$. WBC in group A has very variable matching compared to group B. There is no parallel rise in both groups.

Group B patients have significantly higher mean CRP levels compared to group A patients (50.9 vs. $130 \mathrm{mg} / \mathrm{L})$. While mean WBC count was not significantly different between the two groups inflammatory versus gangrenous (12.90 vs. 12.95) except necrotizing where WBC is 16.2 . This has been shown in prospective study in children $[8,9]$. Study in our patients very well matches with the results of this study where significant proportion of our patients is very well below the age of 16 . CRP value of 50.9 is the level for simple inflammation and suppurative group. Value above this cut-off in our patients was highly predictive of complicated appendicitis. Many studies have shown different levels to predict complicated appendicitis [10]. In complicated cohort of these patients significant rise in reactive proteins should be significantly taken in to account before deciding for conservative treatment in complicated group [11]. Reactive protein cut-off generated in this study can be utilized in deciding the conservative management for simple appendicitis and surgical treatment for complicated appendicitis [12]. Some studies to find the deciding level of CRP between operative treatment and non-operative have failed, and in others raised CRP indicates acute pathology $[13,14]$. Delaying the treatment in complicated appendicitis leads to more complications, longer hospital stay and higher hospital cost. Necrotizing group of our patients though small but had consistent high values of both CRP and WBC and parallel rise providing provisional evidence of emergent treatment in this group to avoid the consequences of perforation and its morbidity. Some studies have debated and suggestion has been made 


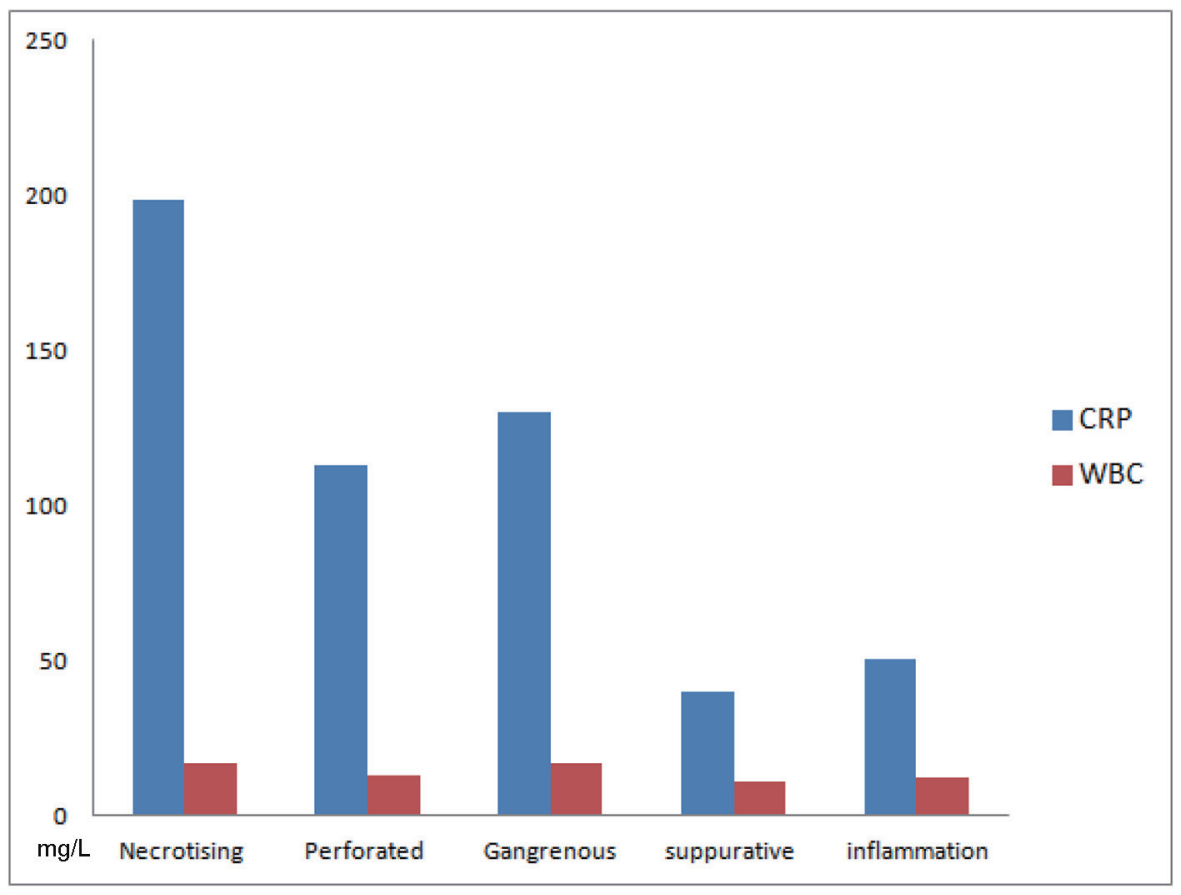

Figure 2. The level of CRP and WBC among different types of appendicitis. Very high CRP is likely to be associated with necrotizing appendicitis, while CRP of 40 or more can be associated with suppurative or inflammatory one. CRP more than 100 and less than 150 may suggest possible perforated or gangrenous appendicitis. Necrotizing appendicitis showed high WBC but the use of WBC may not provide adequate discrimination between different types of appendicitis.

to offer these patients open surgery right from beginning in order to avoid postoperative complications of established infection and collection [15]. In this study procedures were mainly laparoscopic though the figures were small. Surgery should be offered in this group preferably laparoscopic depending on expertise, to avoid mortality in the countries where services are not well organized.

\section{Conclusion}

Our data provided provisional evidence that very high CRP may be related to necrotizing appendicitis, while CRP above $40 \mathrm{mg} / \mathrm{L}$ may suggest suppurative or inflammatory appendicitis.

\section{References}

1. Multicentre observational study of performance variation in provision and outcome of emergency appendicectomy. Br J Surg. 2013;100(9):1240-1252.

2. Cole MA, Maldonado N. Evidence-based management of suspected appendicitis in the emergency department. Emerg Med Pract. 2011;13(10):1-29; quiz 29.

3. Shogilev DJ, Duus N, Odom SR, Shapiro NI. Diagnosing appendicitis: evidence-based review of the diagnostic approach in 2014. West J Emerg Med. 2014;15(7):859-871.

4. Kim HC, Yang DM, Lee CM, Jin W, Nam DH, Song JY, Kim JY. Acute appendicitis: relationships between
CT-determined severities and serum white blood cell counts and C-reactive protein levels. $\mathrm{Br} \mathrm{J}$ Radiol. 2011;84(1008):1115-1120.

5. Gurleyik E, Gurleyik G, Unalmiser S. Accuracy of serum $\mathrm{C}$-reactive protein measurements in diagnosis of acute appendicitis compared with surgeon's clinical impression. Dis Colon Rectum. 1995;38(12):1270-1274.

6. Shakhatreh HS. The accuracy of C-reactive protein in the diagnosis of acute appendicitis compared with that of clinical diagnosis. Med Arh. 2000;54(2):109-110.

7. Asfar S, Safar H, Khoursheed M, Dashti H, al-Bader A. Would measurement of $\mathrm{C}$-reactive protein reduce the rate of negative exploration for acute appendicitis? J R Coll Surg Edinb. 2000;45(1):21-24.

8. Chung JL, Kong MS, Lin SL, Lin TY. Eur J Paed. 1996;155(7):529-531.

9. Gronroos JM, Gronroos P. Leucocyte count and C-reactive protein in the diagnosis of acute appendicitis. $\mathrm{Br} \mathrm{J}$ Surg. 1999;86(4):501-504.

10. Sammalkorpi HE, Leppaniemi A, Mentula P. High admission C-reactive protein level and longer in-hospital delay to surgery are associated with increased risk of complicated appendicitis. Langenbecks Arch Surg. 2015;400(2):221-228.

11. Kim M, Kim SJ, Cho HJ. International normalized ratio and serum C-reactive protein are feasible markers to predict complicated appendicitis. World J Emerg Surg. 2016;11:31.

12. Beecher SM, Hogan J, O"Leary DP, McLaughlin R. An Appraisal of Inflammatory Markers in Distinguishing 
Acute Uncomplicated and Complicated Appendicitis. Dig Surg. 2016;33(3):177-181.

13. Salem TA, Molly RG, O'Dwyer PJ. Prospective study on the role of crp in acute abdomen. Ann R Coll Surg Eng. 2007;89(3):233-237.

14. Davies AH, Bernau F, Salisbury A, Soutar RG. C-reac- tive protein in right iliac fossa pain. J R Coll Surg Edinb. 1991;36(4):242-244.

15. Shelton JA, Brown JJ, Young JA. Preoperative C-reactive protein predicts the severity and likelihood of complications following appendicectomy. Ann R Coll Surg Engl. 2014;96(5):369-372. 